\title{
Twin block appliance: Effect on pharyngeal airway
}

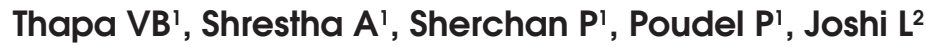

'Vivek Bikram Thapa; 'Amrita Shrestha; 'Prabesh Sherchan; 'Prakash Poudel, Lecturer; ${ }^{2}$ Luna Joshi, Medical Officer; Department of Orthodontics \& Dentofacial Orthopedics, Kathmandu Medical College and Teaching Hospital, Duwakot, Nepal.

\begin{abstract}
Background: Mandibular retrusion is the main cause of Skeletal Class II malocclusion characterized by skeletal retrusion of mandible with skeletal or dentoalveolar protrusion of maxillary.

Objectives: This study was conducted to evaluate effect of treatment with twin-block appliances on pharyngeal dimensions.

Methodology: This study was conducted in in the Department of Orthodontics \& Dentofacial Orthopedics in Kathmandu Medical College. Twenty patients of age group 7 to 14 years with skeletal class II malocclusion with mandibular retrusion were selected. Variables evaluated were depth of nasopharynx; height of nasopharynx; depth of oropharynx; depth of hypopharynx; soft palate length; soft palate thickness and soft palate inclination. The lateral cephalograms were obtained for all subjects before the start of treatment and after a follow-up period of approximately three months in treatment. Results: Results showed that depth of nasopharynx increased by $1 \mathrm{~mm}$, height of nasopharynx increased by $0.78 \mathrm{~mm}$, depth of nasopharynx increased by $1.97 \mathrm{~mm}$, depth of hypopharynx increased by $0.79 \mathrm{~mm}$, soft palate length decreased by $4 \mathrm{~mm}$, soft palate thickness increased by $2 \mathrm{~mm}$ and soft palate inclination decreased by $7.01 \mathrm{~mm}$. The results for depth of pharynx and soft palate thickness were statistically significant.

Conclusion: This study concluded that the use of twin block appliance for class II patients corrects sagittal dimension of oropharynx and hypopharynx. Early intervention for mandibular retrognathism in class II malocclusion helps enlarge the airway dimensions and decrease potential risk of obstructive sleep apnea syndrome for growing patients in the future.
\end{abstract}

Key words: Airway dimension; Class II malocclusion; twin block appliance.

DOI: https://doi.org/10.3126/jkmc.v7i4.23299

\section{INTRODUCTION}

keletal Class II malocclusion occurs in nearly one$\checkmark$ third of the population, the main cause being mandibular retrusion?. By constant forward positioning of mandible myofunctional appliances are designed to stimulate mandibular growth.

Success rate of twin block is more favorable, as it is better tolerated by younger patients. It was proved to be an effective method in promoting mandibular advancement ${ }^{2}$. Symptoms of obstructive sleep apnea syndrome (OSAS) in growing patients has shown a direct correlation with adequate airway. One of the most popular functional appliances is Twin block appliance

Address for correspondence

Dr. Vivek Bikram Thapa

Lecturer, Department of Orthodontics and Dentofacial

Orthopedics,

Kathmandu Medical College and Teaching Hospital

Duwakot, Bhaktapur, Nepal.

E-mail: vivek_thapa@yahoo.com
(TB) with its ability in producing rapid growth changes ${ }^{3,4}$. It has proved to be an effective method for promoting mandibular advancement. All these attributes thereby made it a choice of appliance and is widely used in clinical orthodontics ${ }^{5,6}$. Hence, the study was conducted to evaluate effects of twin block on pharyngeal dimension in skeletal class II malocclusion patients.

\section{METHODOLOGY}

The present study was conducted in the Department of Orthodontics \& Dentofacial Orthopedics of Kathmandu Medical College, Duwakot, Bhaktapur. The ethical clearance for the study was obtained from the Institutional Review Committee, Kathmandu Medical College Teaching Hospital (Ref no: 1004201815) before starting the study. For the study, we selected 20 patients in the age range of 7 to 14 years with skeletal class II malocclusion associated with mandibular retrusion since the age group is at a peak growth spurt during which functional appliances are recommended. All 
patients were of Nepali origin who had come seeking orthodontic treatment to the department. Subjects with history of prior orthodontic treatment, anterior openbite, severe proclination of the anterior teeth, and any systemic disease affecting bone and general growth were excluded from the study. A written informed consent was obtained from the parents or guardians of the subjects after verbally explaining them the procedure of the study. The class II malocclusion in treatment group subjects was corrected by standard twin block appliance. One-step mandibular advancement was carried out during the wax bite registration. An edgeto-edge incisor relationship with 2 to $3 \mathrm{~mm}$ opening between the maxillary and mandibular central incisors was maintained for all subjects. The patients were instructed to wear the appliance for 24 hours, especially during meal times and they were followed once in every four weeks. The pharyngeal airway passage (PAP) dimension was evaluated from lateral cephalograms. The variables evaluated were depth of the nasopharynx (DNP); height of the nasopharynx (HNP); depth of the oropharynx (DOP); depth of the hypopharynx (DHP); soft palate length (SPL); soft palate thickness (SPT) and soft palate inclination (SPI). The lateral cephalograms with teeth in occlusion were obtained for all subjects before the start of treatment and after a follow-up period of approximately four months in treatment (Figure 1).

The statistical analysis of the data was done using Statistical Package for the Social Sciences version 20.0 for Windows. The Student's t-test and Chi-square test were used to check the significance of the data. The $p$-value less than 0.05 was predetermined as statistically significant.

\section{RESULTS}

A total of 20 clients were included in the study. The age of clients ranged from 7-14 years. Number of male clients was nine and female clients was 11 . Table 1 shows the comparative analysis of pharyngeal airway passage variables (PAP) before treatment and after four months of treatment. We observed that DNP increased by 1 $\mathrm{mm}$ from $11.12 \pm 3.87$ before treatment to $12.12 \pm 3.35$ after treatment, HNP increased by $0.78 \mathrm{~mm}$ from 20.19 \pm 4.41 to $20.97 \pm 3.7$, DOP increased by $1.97 \mathrm{~mm}$ from $7.45 \pm 3.31$ to $9.42 \pm 1.88$ post treatment, DHP increased by $0.79 \mathrm{~mm} 12.42 \pm 2.17$ to $13.21 \pm 2.78$, SPL decreased by $4 \mathrm{~mm}$ from $27.19 \pm 4.9$ to $23.19 \pm 3.74$, SPT increased by 2 $\mathrm{mm} 8.18 \pm 2.87$ to $6.18 \pm 1.4$ and SPI decreased by $7.01^{\circ}$ from $49.19 \pm 4.7$ to $42.18 \pm 2.8$ at the end of treatment. The results for DOP and SPT were statistically significant $(p<0.05)$ (Figure 2).

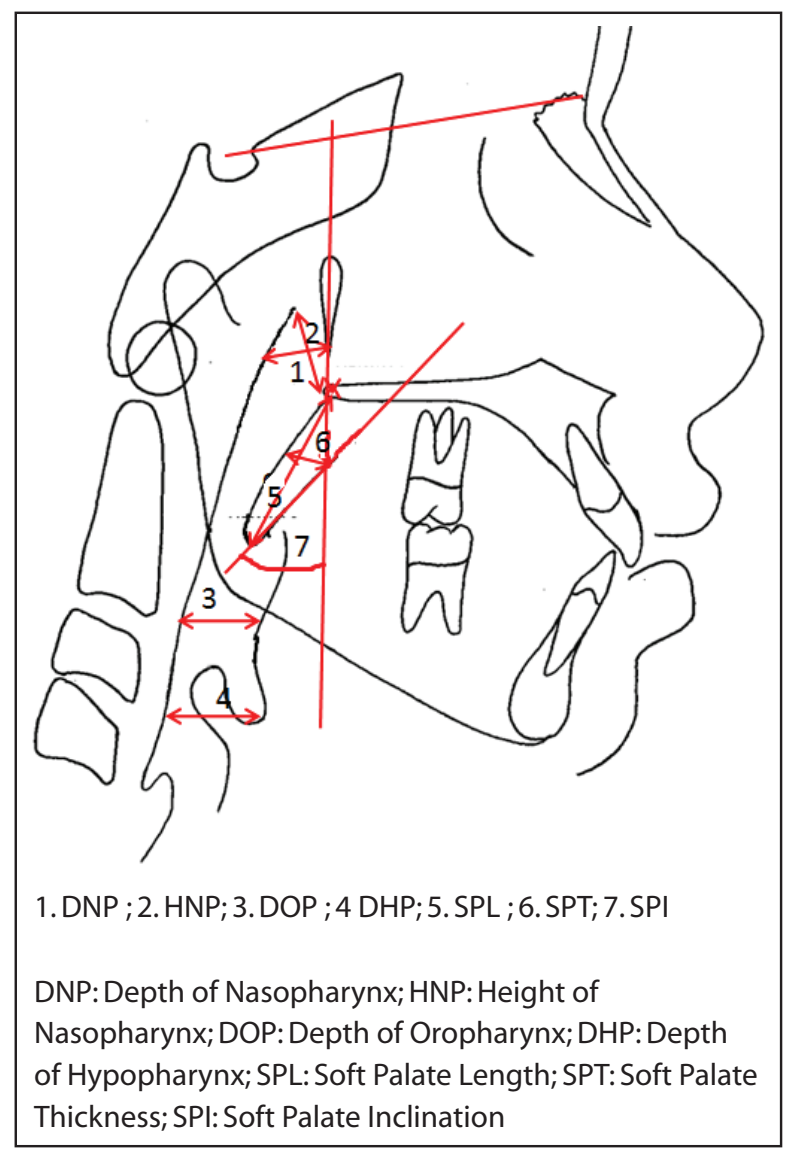

Figure 1: Cephlometric linear and angular parameters

Table 1: Pharyngeal airway passage variables (PAP) before treatment and after four months of treatment

\begin{tabular}{lccc}
\hline Pharyngeal airway passage variables (PAP) & Before treatment & After four months of treatment & p-value \\
\hline Depth of Nasopharynx $(\mathrm{mm})$ & $11.12 \pm 3.87$ & $12.12 \pm 3.35$ & 0.22 \\
\hline Height of Nasopharynx $(\mathrm{mm})$ & $20.19 \pm 4.41$ & $20.97 \pm 3.7$ & 0.18 \\
\hline Depth of Oropharynx $(\mathrm{mm})$ & $7.45 \pm 3.31$ & $9.42 \pm 1.88$ & $0.005^{*}$ \\
\hline Depth of Hypopharynx $(\mathrm{mm})$ & $12.42 \pm 2.17$ & $13.21 \pm 2.78$ & 0.81 \\
\hline Soft Palate Length $(\mathrm{mm})$ & $27.19 \pm 4.9$ & $23.19 \pm 3.74$ & 0.19 \\
\hline Soft Palate Thickness $(\mathrm{mm})$ & $8.18 \pm 2.87$ & $6.18 \pm 1.4$ & 0.55 \\
\hline Soft Palate Inclination $\left(^{\circ}\right)$ & $49.19 \pm 4.7$ & $42.18 \pm 2.8$ & $0.02^{*}$ \\
\hline
\end{tabular}




\section{豆 Before treatment 틀 After 4 months of treatment}

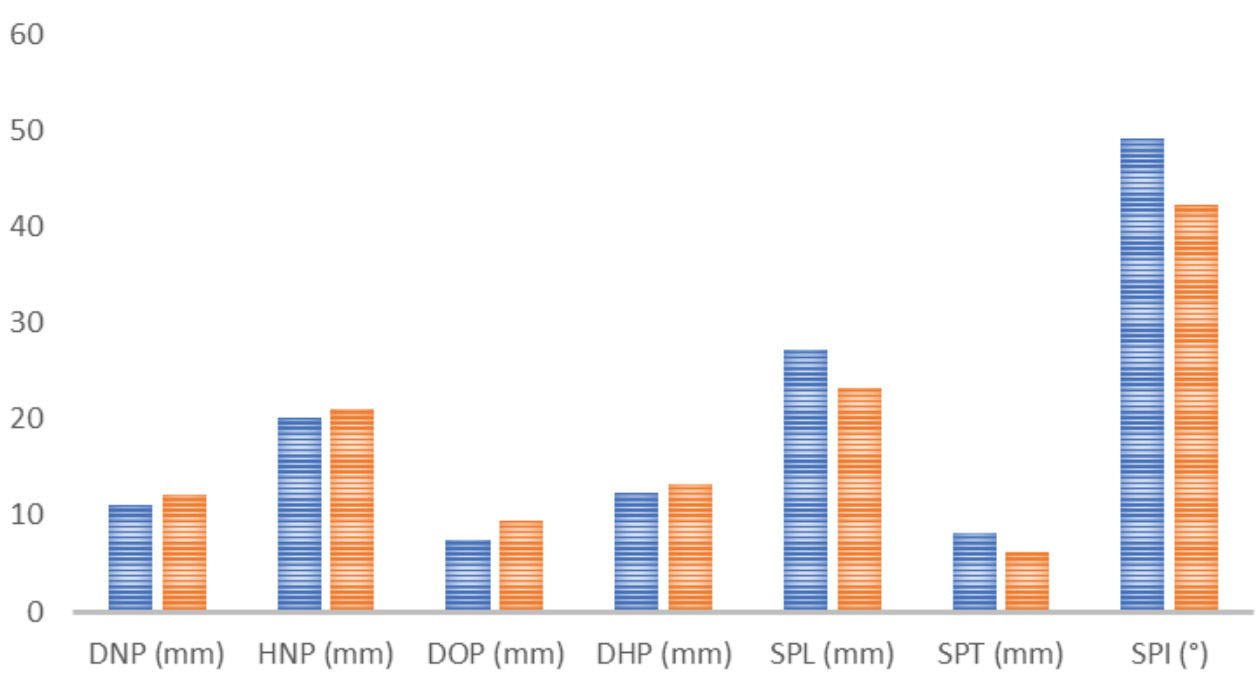

DNP: Depth of Nasopharynx; HNP: Height of Nasopharynx; DOP: Depth of Oropharynx; DHP: Depth of Hypopharynx; SPL: Soft Palate Length; SPT: Soft Palate Thickness; SPI: Soft Palate Inclination

Figure 2: Showing pharyngeal airway passage variables (PAP) before treatment and after four months of treatment

\section{DISCUSSION}

Lateral cephalograms although for airway analysis are not ideal, yet it is very commonly used as an established and reliable tool ${ }^{3}$. Airway dimension on lateral cephalograms are found to be highly accurate. Three dimensional imaging is considered as a method of choice for airway analysis as it would give a three dimensional view of the structure and measurement on all three planes are easily possible as well as volumetric measurement can be established but the disadvantage is that this technique is not available in all centers and has the risk of relatively high radiation dose. Therefore, in numerous airway studies the conventional lateral cephalogram still remains as a valuable and reliable diagnostic tool for such studies ${ }^{7}$.

In subjects with retrognathic mandible small PAP dimension and anatomical adaptation of the soft palate are common features ${ }^{8-10}$. Dimensions of the upper airway by correction of mandibular retrognathism using functional appliances have shown improvement ${ }^{9}, 10$ which is concurrent with our study as well. The present study also showed that the sagittal jaw relationship improved significantly in treatment group subjects. Twin block appliance, postured the mandible forward while a reciprocal force acted distally on the maxilla, restricting its forward growth and simultaneously stimulating forward mandibular growth. Studies on twin block therapy have also reported similar observation ${ }^{11}$. No significant change in the PAP dimensions during adolescence by Hänggi et $\mathrm{al}^{12}$. In our study PAP dimension change seen was very minimum. However, significant improvements in the depth of the oropharynx and hypopharynx, and inclination of the soft palate were seen following correction of mandibular retrusion in class II skeletal malocclusion subjects. The reason considered for decrease in the dimension of the upper airway in subjects with retrognathic mandible is the backward position of the tongue ${ }^{11}$. The Twin block appliance when positions the mandible anteriorly, it influenced the position of the hyoid bone and consequently the position of the tongue improving the overall morphology of the upper airway ${ }^{13}$. Increase in the PAP dimension following myofunctional therapy among subjects with retrognathic mandible has been reported by Jena et al. ${ }^{10}$. Another study on effect of hyoid bone by Schutz et al. ${ }^{14}$ found that after correction, anteriorly positioning of the mandible and the hyoid bone caused an anterior traction of tongue, increasing the posterior airway space as well as reducing the airway resistance. However in contrast to our study, no improvement in oropharyngeal airway dimensions in growing patients were seen following mandibular displacement and maxillary expansion by Fastuca et al. ${ }^{15}$. Oral myofunctional appliance therapy on upper airway dimension has benefitted obstructive sleep apnea (OSA) patients is well established ${ }^{16}$. Similar benefits are also 
produced by various other functional appliances ${ }^{17,18}$. Thickness of the posterior pharyngeal wall in OSA subjects and the effects of oral appliances on the PPWT have been investigated ${ }^{17,18}$. As compared to normal subjects PPWT in subjects with OSA has been reported to be more and the oral appliance therapy had no significant effect on PPWT ${ }^{18}$. However, the present study showed that the PPWT at the nasopharynx, oropharynx, and hypopharynx level was maintained in treatment group subjects, secondary to the forward posture of the tongue caused by anterior relocation of the mandible by twin block appliance. Sagittal dimension of PAP also increased, PPWT thickness got marginally increased it reduced the compensatory adaptation as a result, Cozza et al. in contrast reported that the use of oral appliances in OSA patients had no effect on the thickness of the posterior pharyngeal wall, but it did produce a significant expansion by $13 \%$ in the areas most involved in the collapse ${ }^{19}$. The present study shows that there is a positive impact of twin block appliance therapy on the PAP dimension. Literature also supports that the changes in the PAP dimension following functional appliance therapy are maintained in long term ${ }^{12}$. Thus, twin block appliance used during childhood for class II correction might help to eliminate adaptive changes in the upper airway and predisposing factors decreasing risk of OSA development.

The present study showed the change in pharyngeal dimensions for patients using twin block. The results for DOP and SPT were statistically significant. We observed that DOP and SPT were significantly changed in patients using twin block appliance. The results were compared with previous studies and results were consistent with previous studies. Ghodke $S$ et al. ${ }^{12}$ evaluated the effects of twin block appliance on pharyngeal airway passage (PAP) dimensions and posterior pharyngeal wall thickness (PPWT) in class II malocclusion subjects with retrognathic mandibles. The effect of twin block appliance on PAP and PPWT dimensions were evaluated from lateral cephalograms recorded of appliance therapy in the treatment group subjects and the changes were compared with the changes in the control group subjects. The depth of the oropharynx was increased significantly in the treatment group subjects as compared to the control group subjects. It was concluded that correction of mandibular retrusion by twin block appliance in class II malocclusion subjects increased the PAP dimensions and maintained the pretreatment thickness of posterior pharyngeal wall.
Jena AK et al. ${ }^{11}$ tested the hypothesis that twin-block and Mandibular Protraction Appliance-IV (MPAIV) using lateral cephalograms records concluded twin block appliance as more efficient than MPA-IV. Overall improvement of PAP dimensions was seen and improvement in DOP was also noted among treatment subjects which was similar to our study. Mandibular advancement by the functional appliances caused forward and increased the DOP. Many investigators have also reported a similar observation following various functional appliance therapies. Our study also showed increase in the DOP. Before treatment it showed $12.42 \pm 2.17$ whereas after treatment it improved significantly to $9.42 \pm 1.88 \mathrm{~mm}$. The greater improvement in the DOP among twin block subjects could be due to more forward movement of the mandible and relocation of the tongue.

Cone beam computed tomography (CBCT) study by Li L et $\mathrm{a}^{20}$ evaluated morphological changes of upper airway after Twin block treatment in growing patients and untreated Class II patients with mandibular retrusion and compared the two set of samples. They concluded on comparison treated patients showed a significant enlargement in the hypopharynx and oropharynx. Transverse shape in the oropharynx also became more elliptical. Hyoid bone also moved to an anterior position after TB treatment.

Treatment effects of functional appliances (FAs) on upper airway dimensions on patients with mandibular retrognathism were evaluated by Xiang $M$ et al. ${ }^{21}$ who concluded that FAs can enlarge the upper airway dimensions, specifically in the oropharyngeal region. Therefore, early intervention for mandibular retrognathism in class II malocclusion helps enlarge the airway dimensions and decrease potential risk of obstructive sleep apnea syndrome for growing patients in the future. Along with the functional effect myofunctional appliance also help to correct class II malocclusion as an interceptive orthodontics providing an overall improved esthetic of the facial profile.

Only linear measurements were taken in studies involving lateral cephalograms. The literature is divided about the accuracy in measuring airway spaces dimensions using lateral cephalograms, with the main concern being inadequacy to give a three-dimensional perspective. CBCT and Cephalometric imaging provide sufficient and accurate data to analyze airway dimensional changes in nasopharynx, hypopharyngeal and oropharynx areas. 


\section{CONCLUSION}

$\mathrm{CBCT}$ and Cephalometric imaging provide sufficient and reliable data to analyze airway dimensional changes in nasopharynx, hypopharyngeal and oropharynx areas. We can conclude that early intervention for mandibular retrognathism in class II malocclusion helps enlarge the airway dimensions and decrease potential risk of

\section{REFERENCES}

1. Proffit R,Fields HW Jr., Moray LJ. Prevalence of malocclusion and orthodontic treatment need in the United States: Estimates from the NHANES III survey. Int J Adult Orthodon Orthognath Surg. Volume 13;Issue no 2; Page no: 97-106. [PubMed]

2. McNamara JA Jr., Brudon WL. Orthodontics and Dentofacial Orthopedics. Am J Orthod Dentofacial Orthop.2006;129:S71-41.[Full Text]

3. Abdelkarim A. A cone beam CT evaluation of oropharyngeal airway space and its relationship to mandibular position and dentocraniofacial morphology. JWFO;1 (2), June 2012, Pages e55-e59,. [PubMed]

4. Hakan EL, Palomo JM. Airway volume for different dentofacial skeletal patterns. Am. J. Orthod. Dentofacial Orthop. June 2011;139(6):511-21[PubMed]

5. Vieira $B B$, Itikawa $C E$, de Almeida $L A$, Sander $H H$, Aragon DC, Anselmo-Lima WT et. al . Facial features and hyoid bone position in preschool children with obstructive sleep apnea syndrome. Eur Arch Otorhinolaryngol. 2014;271(5):1305-9. [Full Text]

6. Hong JS, Oh KM, Kim BR, Kim YJ,Park YH. Threedimensional analysis of pharyngeal airway volume in adults with anterior position of the mandible. Am. J. Orthod. Dentofacial Orthop. 2011;140(4): e161-9.[PubMed]

7. Battagel JM, Johal A, Kotecha B: A cephalometric comparison of subjects with snoring and obstructive sleep apnea. Eur J Orthod. 2000;22(4):353-65.[Full Text]

8. Ozbek MM, Memikoglu TUT, Gogen H, Lowe AA, Baspinar E. Oropharyngeal airway dimensions and functional orthopaedic treatment in skeletal class 2 cases. Angle Orthod.1998;68(4):327-36 [Full Text]

9. Muto T, Yamazaki A, Takeda S. A cephalometric evaluation of the pharyngeal airway space in patients with mandibular retrognathia and prognathia, and normal subjects. Int J Oral Maxillofac Surg. March 2008;37( 3):228-31.[PubMed]

10. Jena AK, Singh SP, Utreja AK. Effectiveness of twinblock and Mandibular Protraction Appliance-IV in obstructive sleep apnea syndrome for growing patients in the future.

Along with the functional effect myofunctional appliance also help to correct class II malocclusion as an interceptive orthodontics providing an overall improved aesthetic of the facial profile.

the improvement of pharyngeal airway passage dimensions in Class II malocclusion subjects with a retrognathic mandible. Angle Orthodontist. 2013;83(4):728-34.[PubMed]

11. Hänggi MP, Teuscher UM, Roos $M$, Peltomäki TA. Long-term changes in pharyngeal airway dimensions following activator-headgear and fixed appliance treatment. European Journal of Orthodontics. December 2008; 30(6):598-605. [Full Text]

12. Ghodke S, Utreja AK, Singh SP, Jena AK. Effects of twin-block appliance on the anatomy of pharyngeal airway passage (PAP) in class II malocclusion subjects. Progress in Orthodontics 2014; 15(1): 68. [Full Text]

13. Schutz TCB, Dominguez GC, Hallinan MP, Cunha TCA, Tufik S. Class II correction improves nocturnal breathing in adolescents. Angle Orthodontist. 2011;81(2):222-8. [Full Text]

14. Fastuca R, ZeccaPA, Caprioglio A. Role of mandibular displacement and airway size in improving breathing after rapid maxillary expansion. Progress in Orthodontics,April 29 2014;15:40.[Full Text]

15. Farronato G, Storti E, Cuzzocrea ML, Lucchese A, Cossellu G, Assandri $F$ et. al. Three-dimensional changes of the upper airway in patients with obstructive sleep apnea syndrome after a nonadjustable oral appliance treatment. Minerva Stomatol.2013;62:107-16. . [Full Text]

16. Sakakibara $H$, Tong $M$, Matsushita K, Hirata $M$, Konishi Y, Suetsugu S. Cephalometric abnormalities in non-obese and obese patients with obstructive sleep apnoea. European Respiratory Journal1999;13:403-10.[Full Text].

17. Zha D, Qiao L, Ge Y, Deng Z, Xue T, Liu Y et. al. The MRI study of upper airway on obstructive sleep apnea hypopnea syndrome. Lin chuang er bi yan hou tou jing wai ke za zhi.Journal of clinical otorhinolaryngology, head, and neck surgery. 2008; 22(13):593-6.[PubMed]

18. Cozza P, Ballanti F, Castellano M, Fanucci E. Role of computed tomography in the evaluation of orthodontic treatment in adult patients with obstructive sleep apnea syndrome (OSA) .Progress in orthodontics. 2008; 9(1): 6-16.[PubMed] 
19. Li L, Liu H, Cheng H, Han $Y$, Wang $C$, Chen $Y$ et. al. CBCT evaluation of the upper airway morphological changes in growing patients of class II division 1 malocclusion with mandibular retrusion using twin block appliance: a comparative research. PLoS One. 2014 Apr 4;9(4):e94378. [PubMed]
20. Xiang M, Hu B, Liu Y, Sun J, Song J. Changes in airway dimensions following functional appliances in growing patients with skeletal class II malocclusion: A systematic review and meta-analysis. International Journal of Pediatric Otorhinolaryngol. June 2017; 97:170-80.[PubMed] 